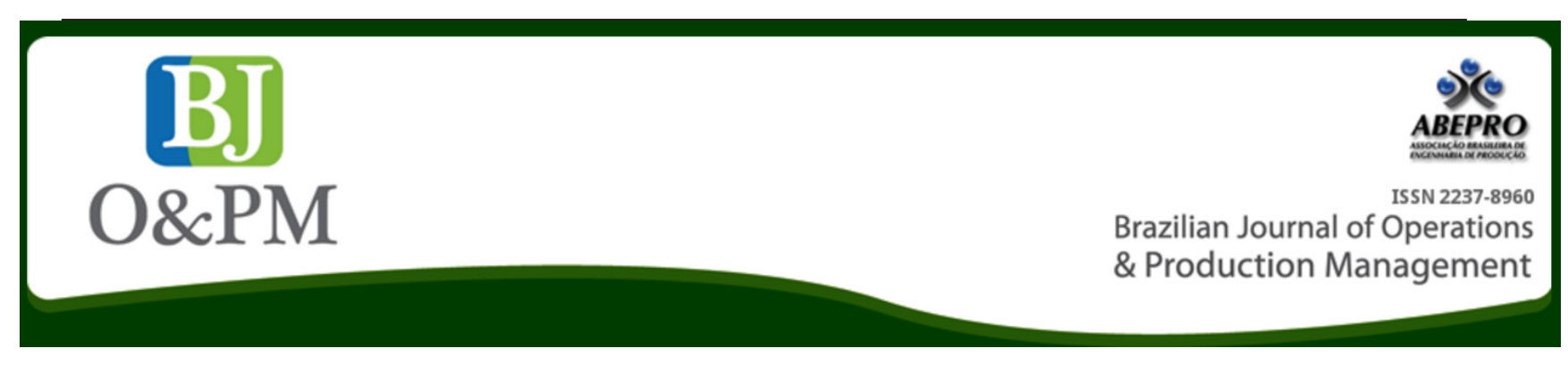

\title{
THE DESIGN THINKING AND THE HEALTH SERVICES: THE COMPETITIVE DIFFERENTIAL THROUGH THE HUMANIZATION OF PATIENT EXPERIENCE
}

\author{
Adriano Amaral Caulliraux $x^{a}$; Marcelo Jasmim Meiriño ${ }^{a}$ \\ ${ }^{\text {a }}$ Federal Fluminense University (UFF) - Niterói, RJ, Brasil
}

\begin{abstract}
It is necessary to rethink the different experiences of patients in health care area. Feelings such as anxiety and fear, for example, are common in the interactions between caregivers and patients, which reflect the disparity between the offered and the necessary to meet the patients' demands. In this article, there will be analyzed two cases of successful application of the Design Thinking in the Health Care area, the "Mayo Clinic" - elected the best hospital in the USA in 2014 - and the "Humanization of the perioperative experience of the elective patient" - a Master's thesis developed by the author at Fluminense Federal University (UFF) in 2015. It is demonstrated the potential of using the Design Thinking for the systematic planning and re-planning of the health service, seeking to meet and transpose the human beings expectations, generating values for the clients, market spread and leveraging a competitive advantage.
\end{abstract}

Keywords: Health Services, Design Thinking, Humanization.

\section{INTRODUCTION}

The evolution of the health services exceeded the same paradigms of the value creation models, the centralization and sequencing to more open and distributed ones, in which the citizens take part in the co-creation of their own welfare. The first stage is the mass production, a Fordist model of care providing, where the patients arrive sick in the system and the doctors, with their specialized knowledge, treat and heal them As soon as the value perception changes from cost to quality, the model of mass customization is adopted. Although adopting a sequential approach of value creation, it adapts the service in order to meet the specific demands of the clients. Lastly, there is an evolution to a model of mass collaboration, in where the challenges of the health area are more complex and the epidemiological profile becomes more intense in chronical diseases, the co-production of services, counting on the involvement of patients and society, is essential for the sustainability of the health system (FREIRE; SANGIORGI, 2010).

The designers are among the ones who will contribute to make the world more human. As the creators of the models, prototypes or propositions, the designers occupy a dialectical space between the world that "is" and the one that "could be?" Although informed by the past and by the present, their act is oriented to the future and occurs through the interventions that are tested in the social world. Such interventions must focus in factors that satisfy the human beings, assure their welfare and are economically viable (MARGOLIN, 2007).

It is necessary to rethink the different experiences of patients in the health area. Feelings as anxiety and fear, for example, are common in the interactions between caregivers and patients, what reflects the disparity between what is offered and what is necessary to meet the patients' demands. The Design Thinking is a methodology that successfully integrates theories and methods from distinct areas, and its synergy with the health area has been optimizing and humanizing the experiences of patients care (MULLANEY et al.,2012).

In this article, it will be presented two cases in where the Design Thinking has being successfully applied in the redraw of the Health service - "Mayo Clinic" and the "Humanization of the perioperative experience of the elective patient". The analysis about the Mayo Clinic was performed through the systematic review of academic and technical literature, and the case of the humanization of elective perioperative flow was developed by the author, where there were performed 20 semi-structured interviews with health professionals, 20 interviews with ex-patients, 50 hours of standardized observation, visits to 2 hospitals which provide perioperative services, besides moments of co creation and prototyping. 


\section{LITERATURE REVIEW}

In the following topic, there is a summary of the literature review, conducted for this research will be presented, based on the following themes: Design Thinking; Health Service; Design Thinking applied to health Service.

\subsection{Design Thinking}

Martin (2009) presents - based in the thought of the scientist Charles Sanders Peirce- that the Design Thinking follows a third way of thinking, besides the deduction and induction, the abductive thought. As Pierce indicates, "we should never commit to the truth of current scientific opinion, but instead, we must accepted it just as a stage towards to the truth" (GARVEY \& STANGROOM, 2009). This way of thinking establishes a parallel between the decisions based on data of the analytical world, and the feeling that lacks of the intuitive data, breaking the mystery of "how could it be?" trying and analyzing the possible answers for the present problems.

The Design Thinking searches for solutions of complex problems, redefining the way they are interpreted, and consequently, how they are solved (CAULLIRAUX et al.,2013). It is recurrent in the literature the attempt to categorize the basic premises of the area, among which are: holistic view - the whole system must be considered; user-centered - focused in the real needs of the user; co creative - the key employees must be involved in the creation process; visual thought - capacity of expression developed by years of training of a designer; prototyping - the concepts must be tested and enhanced in partnership with the final users (CAULLIRAUX, 2014).

The Design Thinking has as expectation the constant transposition of the known solutions through the exploration of the unexplored territories. Its process must be systematic, however, it cannot be rigid, the flexibility of the thought and the exploration are the key concepts. It is expected from the Designer an entrepreneurial approach, even when the idea has already started to be developed by its client, and the development cycle is short due to the market restrictions (GOLDSCHMIDT; RODGERS, 2013).

The quality of design is closely related to its ability to connect and create relationships with its users. In other words, the main objective is to understand the cultural issues of humanization, which allows the construction of this relationship. Such issues are linked to the social interactions and emotions that define the users' experience (MOOTEE, 2013).

\subsection{Health Services}

Throughout history, medicine has improved, teaching the new health professionals the best practices that must be replicated, what makes it the antithesis of change. The healthcare environment is perfectly orchestrated in order to reduce the variance, based on quantitative analyzes and the standardization of care due to the "welfare" of the patient. What is sought in fact is reducing costs through process optimization, without sticking to the perception of quality through the perspective of the client. (DICKSON et al.,2011).

During the last years, significant changes have been occurring in the industry of the health service in the whole world. In one hand, the growing demand for universal access to health services. On the other hand, the fast technological innovation in the medicine is responsible to make the costs in the sector to increase unsustainably. The growing pressure for better cost management, associated with an increasingly strong regulatory, drives to the sector professional movement, seeking better levels of efficiency and effectiveness (PENA; MALIK, 2011).

The dehumanization reigns in health services management and it can be identified in factors such as: poor relationship between professionals and users, devaluation of inter subjectivity, disease commercialization, scrapped material and equipment, lack of strategic participative management, besides the very dissatisfaction of all employees with the health system (SILVA; MUNIZ, 2011).

The health services cannot be understood as organizations where economic and political issues are obstacles to the provision of adequate patient care. Besides the individual obligations of the professionals involved in the care taking, there is the moral responsibility of the manager in the implementation of policies and actions guided by ethics, seeking the improvement of institutional quality standards (FORTES, 2011).

The cultural transformation guided by the humanization of practices and health services management is based on an ethical attitude of respect for human beings, a host welcome, the understanding of the patient as a citizen and not only as a temporary consumer of a health service (FORTES, 2011).

In the industry of health,-it is important to understand, by the point of view of the family and the patients, what aggregates value during the service usage experience. According to the studies of the Institute of Medicine, the positive perception about the care experience directly influences the speed and quality of its clinical improvement. Another point is that environment factors tend to directly affect the emotional patients, families and staff (LEE, 2011). 


\subsection{Design Thinking applied to the Health Service}

Within the last two decades, the health industry has been suffering changes in the way they project services. These changes are propelled by different reasons, especially to: higher customer expectations about services, constant advancement of technology, greater access to information in the digital media and the adoption of a holistic approach for health and welfare purposes. The health service project performed through the Design Thinking, focused on the humanization of the patient experience and on the constant improvement of the care providing, will generate results that satisfy their clients and consequently, have their loyalty (LEE, 2011).

The humanization can be reached through the usability, the user's experience, brand proposal, among other 'human' factors. All the employees are part of the "experience network" in question, and the humanization may occur in all these complementary axes. By allowing the users to externalize their humanity into the organization, this will became part of their lives and contact network, promoting sustainability and growth (MOOTEE, 2013).

In order to identify the real needs of the patient, it is necessary to share his/her experience, what happens through the observation, interviews, behave analyses, among others. The ability to articulate, produce, build and decode knowledge is the essence of design thinking, always keeping the focus on the user, on the human being (BELLUCCI; MARTINS, 2012).

The Design Thinking has the capacity of expanding the scope of solutions that permeates the patient's experience in human health. Through its holistic approach and focused in the implicit and explicit needs of the human being, it must be considered as an instance of specific analyzes their emotional welfare, innovating in areas usually neglected in the market (MULLANEY et al., 2012).

As advance the training and methods that approach the health through Design Thinking, the possibilities of synergy between these two fields are becoming infinite. It is not only about redraw the actual and obsolete health service systems, but it is about transcend the physical limits of the clinics toward reality experienced by people and communities, where health is really defined (FREIRE; SANGIORGI, 2010).

\section{CASE STUDIES}

Below, will be presented two cases in where it was applied the Design Thinking for the redraw of the health service - "Mayo Clinic" and the "Humanization of elective perioperative flow". The Mayo Clinic - elected the best hospital in the USA in 2014 - besides being entirely designed on the principles of Design Thinking, it develops systematically innovation in its products, services and strategies through this methodology. The "Humanization of elective perioperative flow" was a Mater Degree's research developed at UFF (Federal Fluminense University), and used the Design Thinking as a guiding methodology.

Firtsly, it will be described the context in where the mentioned case was developed, the used methodology will be presented, so finally the main results will be exposed.

\subsection{Mayo Clinic - Center for Innovation}

\section{Context}

A case study performed by Yale Business School (2012), deeply approached the Mayo Clinic. The traditional American hospital chain has already noticed that for more than 50 years, despite the remarkable advances in diagnosis and diseases' treatment, the health system itself had changed very little. Motivated by the belief that by improving the way of providing care it would be possible to better use the scientific advances, they started in 2002 - using IDEO's consultancy - a lab called SPARC, where the doctors, patients and other employees could test hypothesis about new ways of interaction between health professional and its users.

After six years of experience, the lab evolved into a dedicated center - Center for Innovation (CFI) - that works as a kind of an incubator for new ideas to be achieved. The new concepts explore all the stages of the care supply, considering the preventive health, the initial contact made by phone, the medical appointment, the diagnosis, the problem treatment and the aftercare.

\section{Methodology}

The divergent thinking is the key for the fusion of the Design Thinking with the medical practice in the Mayo Clinic. By bringing together professionals from different disciplines in conducting participatory research centered on the human being - the essence of the Design Thinking - the issue is framed and developed under a light different from the usual. The work process includes planning, research, synthesis, prototyping and implementation. (DICKSON et al., 2011) 

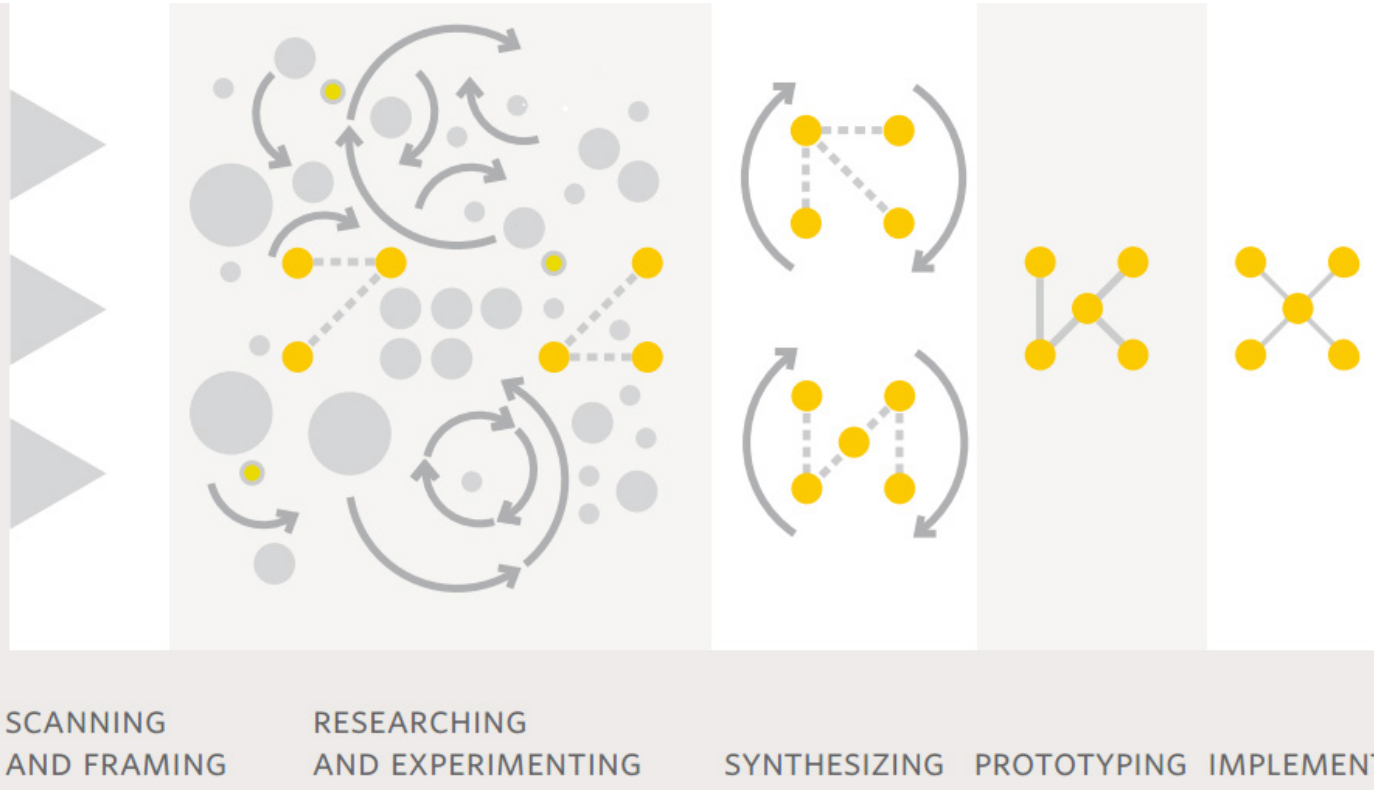

RESEARCHING

AND EXPERIMENTING

SYNTHESIZING PROTOTYPING IMPLEMENTING

Figure 1: Methodology Center for Innovation - Mayo Clinic

Source: Dickson et al., 2011

The main point of the process is the research, through which the current scenario is mapped, allowing the coherent idealization of future scenarios. In the experimentation phase, one seeks to achieve promptly several concepts, aiming its fast trial and the insights generation. In the synthesis stage, the several findings are organized and prepared for the prototyping, through which the concepts will be achieved, tested, evaluated and refined. (DICKSON et al., 2011).

As indicated by the CFI's managing director:

The field research help us to understand the real needs of the patient, and it will guide the improvement of the patient's experience. The Program goes much further than redraw the exam rooms and equip them with luxurious furniture. It's about the process and the patient's care flow, how and where the interactions between the patients and care providers occur, and how to integrate most efficiently, the technology with the patient's experience. (mayoclinic.org, 2015 - available at: mayoclinic.org, 2015)

\section{Results}

In order to change the traditional care model of Mayo Clinic, the CFI, initially understood what led the clients to look for the hospital - high quality and specialized care. By understanding the essence of the value proposition, the CFI was able to start to explore and develop based in their clients' demands. The objective was to migrate from the old centralized model of care, to a concept of integrated care delivery network, which aims to be connected to 200 million people in 2020 (AGUIRRE; VINK, 2013).

The innovation needs propitious environment to happen. Therefore, the CFI possesses several specific spaces to develop new concepts. The "Healthy Aging and Independent Living Lab", for example, is an initiative performed together with a local institute, in where live 400 elderly. A lab was created in loco, consisting of an area for common use of residents. In this area, new products and services what may facilitate the independent and health life of the elderly, are tested (AGUIRRE; VINK, 2013).

\subsection{Humanization of the perioperative experience of the elective patient}

\section{Context}

The perioperative period involves the steps of the pre operatory, trans operatory and post operatory, each one of them with its specificities. Seeking to meet their bio/psych/ social - besides the emotional and spiritual needs, it's the health professional's responsibility to establish an efficient and personalized interaction with the client, fulfilling his/her needs in these various spheres (CHRISTÓFORO; CARVALHO, 2009). The experience of the disease and the surgery generates stressed feelings and reactions in the patient and his/her family, by the preparation, by the surgical-anesthetic procedures and by the recovering, making them vulnerable and depending (LOPEZ; LA CRUZ, 2001).

The word surgery is something that drives the human being to make endless reflections. It does not matter how simple 
the surgery is, it will possibly be followed by anxiety, doubts and fear (BELLUOMINE; TANAKA, 2003). The justification of this research is found in the lack of humanization proposals for the perioperative flow as a whole, whereas, after mapping through horizontal literature review as well as field visits, one observed that the texts about humanization, approach the theme in a partial way, and usually from the perspective of the involved health professionals. The use of Design Thinking methodology justifies itself by its proposal of comprehension, focused in the human being through a holistic and collaborative approach, besides the several cases mentioned in the literature about the success of its application in the health area.

\section{Methodology}

Inspired mainly by the double diamond methodology, the research in question was structured according to 3 big stages: Theoretical Knowledge; Proposal Formulation; Implementation - which are unfolded into 6 steps - Literature Review; Current State of Practice; Synthesis; Co creation Prototyping; Co creation - Deepening; Final Proposition. The figure below summarizes the main methods used and the objectives of each step of the research:

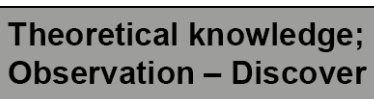

\section{Proposal formulation - \\ Definition and Development}

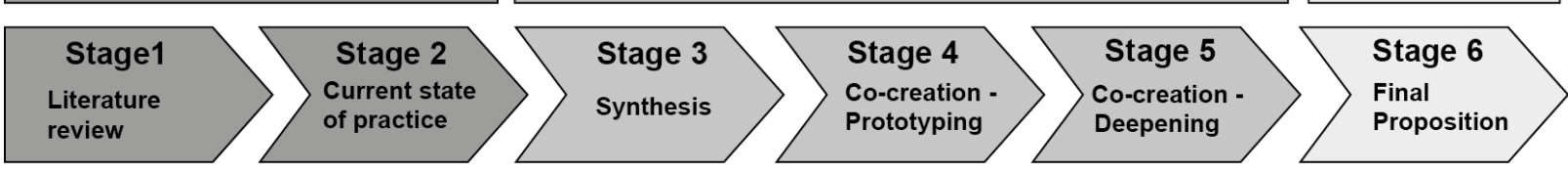

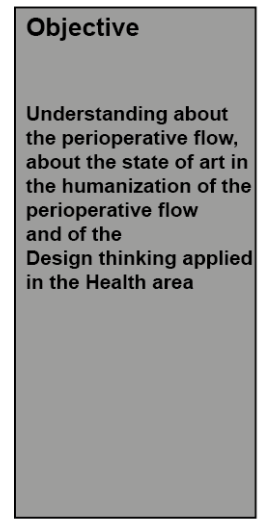

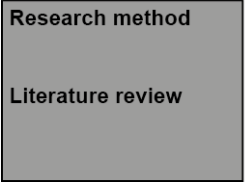

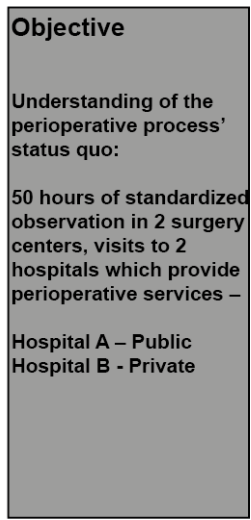

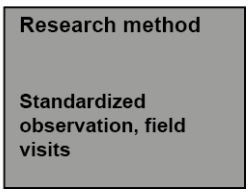

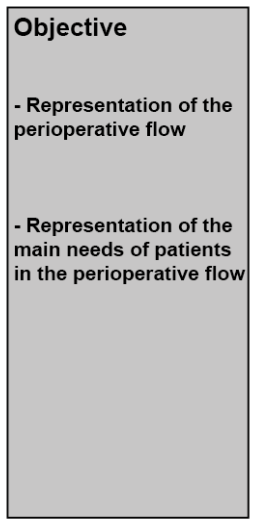

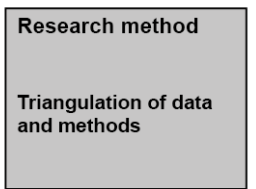

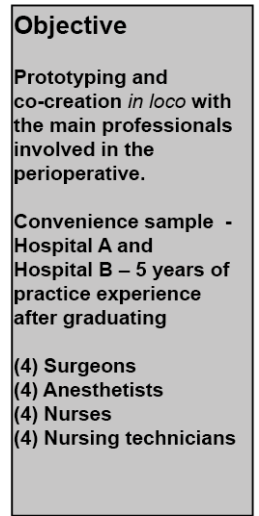

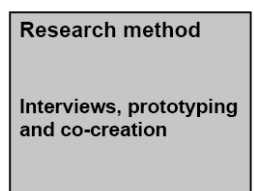

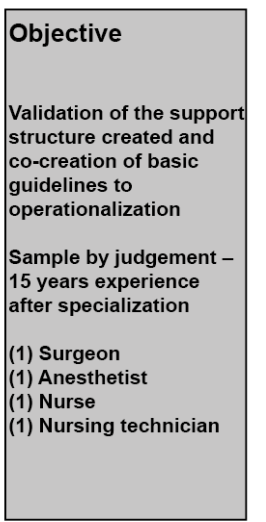

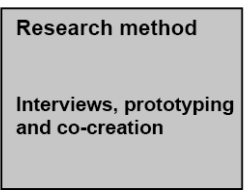

\section{Implementation}

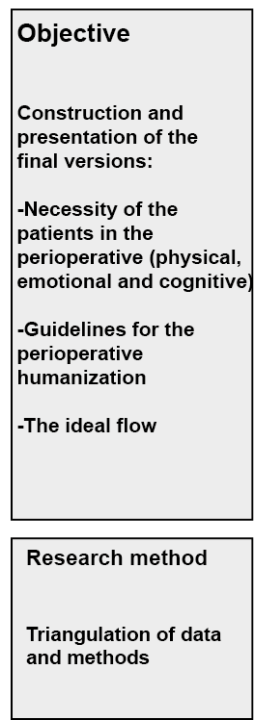

Figure 2: Methodology - Humanization of the perioperative experience of the elective patient

Source: Caulliraux, 2015

There were 20 interviews conducted with former surgical patients, 20 interviews with health professionals involved in the perioperative, 50 hours of standardized observation in 2 surgery centers, visits to 2 hospitals which provide perioperative services, review of national and international related literature, besides prototyping and co creation moments with the involved employees.

Through the first three stages, the researcher acquired knowledge about the state of art and about the status quo of the studied phenomenon - perioperative flow, while during the last three stages, in addition to the empathy development with employees, the concepts have been tested and improved collaboratively.

\section{Results}

Several prototypes were created, tested and refined in loco, enabling the understanding of the needs of patients in physical, emotional and cognitive levels, during the 16 stages of the perioperative. Based on the mapped needs, 28 guidelines were proposed for the humanization of the perioperative, and then performed a narrative exercise about the humanized flow.

The results seek to ensure the quality and safety of the patient, the provision of all necessary information, the ambience in order to have comfort and privacy, the team training to access the minimum communication protocols, 
the creation of a virtual portal for teaching and co-creation, besides other proposals that seek value and meet the needs of patients in the perioperative.

\section{THE DESIGN THINKING AND THE HEALTH SERVICES}

As it has been observed in Mayo Clinic's case, the Design Thinking was first used to understand the potential of the Institution in terms of internal resources, clients, market positioning and value proposal. After the development of some interventions in the Hospital, it was created an attachment to the same laboratory, whose mission is to innovate consistently in the interaction between patients and the Mayo Clinic, using the Design Thinking as a guiding methodology.

In the case of the humanization of perioperative flow of the elective patient, firstly they were held moments of observation and field visits, interviews of health professionals and former patients, for in the end, to be performed moments of prototyping and co-creation. Through the Design Thinking, the Researcher understood the real human needs and proposed guidelines for the humanization of the perioperative flow, besides a narrative inference about humanized flow.

In the described cases, it was shown the potential of using the Design Thinking for the systematic planning and re-planning of the health services, seeking to meet and overcome the expectations of human beings. The management of the health organizations, as shown by Mayo Clinic, can benefit from the methodology of Design Thinking through constant research, adequacy and innovation in its services, providing a differentiated value proposition and leveraging a competitive advantage.

\section{CONCLUSION}

The Design Thinking is a methodology focused on discovering and generating invents that supply - and transpose - implicit and explicit needs of the human beings. For this reason, its potential application in projects that seek the "humanization of health" is evident, due to the specialty field - guided by synergy and interdisciplinarity with the social sciences - to grasp holistically both the phenomenon in question as the demands of the involved human beings

As a natural increasing tendency since the Industrial Revolution, the expansion of supply has forced companies to differentiate themselves in order to support, or even reach, the competitive advantage. The methodologies brought by the Design field seek the understanding of the real needs of the clients, as well as the creation of new spaces for competition. It is expected that the market, increasingly demands the innovation potential offered by the Design, seeking the differentiation based on the human values to thrive.

The introduction of the Design Thinking tools in the management of the health service - as the investigation focused in the human being, prototyping and co-creation corroborates with the migration from the Fordist model of care delivery for a mass collaboration model, in which the society is empowered and co-responsible for the results of the health system.

\section{REFERENCES}

Aguirre, M. and Vink, J. Catalyzing Systemic Transformations in Health Care -Lessons learned by design practitioners at Mayo Clinic Center for Innovation. OSLO: Relating Systems Thinking and Design 2013, 2013.

Bellucci, M. and Martins, R. (2012) Contribuições de Design Thinking à humanização do tratamento de câncer infantil. Londrina: Projética Revista Científica de Design Vol. 3, No.2

Belluomini, A. and Tanaka, L. (2013) Assistência de enfermagem no pré-operatório de cirurgia cardíaca. São Paulo: Ed. Ferreira \& Bento

Bezerra, José Tarcisio Mendes. Humanização da Assistência do Enfermeiro em Centro Cirúrgico. 2007. 39f. TCC (Bacharel em Enfermagem) Centro Universitário de Brasília. Uniceub, Brasília

Biazin, D.; and Coldibelli, L. and Ribeiro, R. and Silva, M. and Andrade, M. and Flauzino, E. and Lara, F. (2002) Importância da assistência humanizada ao paciente submetido a cirurgia cardíaca. Revista Terra e Cultura, No.35

Brown, T. (2009) Design Thinking: Uma metodologia poderosa para decretar o fim das velhas ideias. Rio de Janeiro: Elsevier

Caulliraux, A. and Proença, P. and Cardoso, V. (2013) Synergies between Strategic Design and Roadmapping: a development roadmap for the Rio de Janeiro State Biotechnology Cluster. University of Cambridge: Cambridge Academic Design Management Conference (CADMC 2013)

Caulliraux, A. Design Thiking: Criando com (e para) seus clientes (2014). Rio de Janeiro: X Congresso Nacional de Excelência em Gestão

Caulliraux, Adriano Amaral. Proposta de Método para Aplicação do Design Thinking em Serviços de Saúde: O Caso do Fluxo Perioperatório do Paciente Eletivo. (2015) $131 \mathrm{f}$. Dissertação (Mestrado em Sistemas de Gestão). LATEC, Universidade Federal Fluminense, Niterói

Christóforo, B. and Carvalho, D. (2009) Cuidados de enfermagem realizados ao cliente cirúrgico no período préoperatório. Rev Esc Enferm USP, vol.43, No.1 
Dickson, B. and Friedman, E. and Ross, L. (2011) Innovating in Health Care - an Environment Adverse to Change. Touchpoint: The Journal of Service Design, Vol.3, No.2, Pages 48-53

Fortes, P. (2011) Breve reflexão sobre aspectos da gestão de serviços de saúde. In: Neto, G. and Malik, A. Gestão em Saúde. Rio de Janeiro: Guanabara Koogan

Freire, K. and Sangiorgi, D. (2010) SERVICE DESIGN \& HEALTHCARE INNOVATION: from consumption to coproduction and co-creation. Linköping: Second Nordic Conference on Service Design and Service Innovation

Garvey, J. and Stangroom, J. (2009) Os Grandes Filósofos. São Paulo: Editora Madras

Goldschmidt, G.; Rodgers, P. (2013) The design thinking approaches of three different groups of designers based on self reports. Design Studies, Vol. 34, No.4

Lee, S. (2011) Evaluating Serviceability of Healthcare Servicescapes: Service Design Perspective. International Journal of Design, Vol.5, No. 2

Lopez, A. and La Cruz, M. (2011) Hospitalização. Rio de Janeiro: McGraw-Hill

Margolin, V. (2007) Design, the Future and the Human Spirit. Design Issues, Vol. 23, No. 3

Marinelo, G. and Jardim, D. (2013) Estratégias lúdicas na assistência ao paciente pediátrico: aplicabilidade ao ambiente cirúrgico. Revista SOBECC, Vol. 18, No. 2

Martin, R. (2009) The Design of Business. Why design thinking is the next competitive advantage. Boston: Harvard Business School Press Book

Mootee, I. (2013) Design Thinking for strategic innovation. New Jersey: John Wiley \& Sons

Mullaney, T. and Pettersson, $H$. and Nyholm, T.and Stolterman, E. (2012) Thinking beyond the cure: A case for human-centered design in cancer care. International Journal of Design, Vol. 6, No.3, Pages 27-39

Pena, F. and Malik, A. (2011) Gestão Estratégica em Saúde. In: Neto, G. and Malik, A. Gestão em Saúde. Rio de Janeiro: Guanabara Koogan

Silva, N. and Muniz, H. (2011) Vivências de trabalhadores em contexto de precarização: um estudo de caso em serviço de emergência de hospital universitário. Estudos e Pesquisa em Psicologia, Vol. 11, No. 3

Yale school of management. (2012) Mayo Clinic: Design Thinking in Health Care. Yale University 